\title{
EVALUATION OF DRIVER BEHAVIOR TO HYDROPLANING IN THE STATE OF FLORIDA USING DRIVING SIMULATION
}

\author{
Claude Villiers, Ph. D. ${ }^{{ }^{*}}$ \\ Dahai Guo, Ph. D. \\ ${ }^{1}$ Department of Environmental \& Civil Engineering, Florida Gulf Coast University, 10501 FGCU \\ Blvd. S. Fort Myers, Florida 33965
}

(Received: November 2019 / Revised: December 2019 / Accepted: December 2019)

\begin{abstract}
This project used a driving simulator to investigate patterns of drivers' behavior during rainfall events using different geometries. The researchers conducted a literature review of previous transportation studies using driving simulators and selected and analyzed extensive field data on major highway sections throughout Florida. The driving simulator at the University of Central Florida simulated the parameters such as speed and rainfall intensity observed in the field. Based on an analysis, the researcher found that drivers are not affected by light rainfall events. However, heavy rainfall has a significant impact on their speed; on average drivers reduced their speed by 6 to $12 \mathrm{mph}$. Also, there is no interaction between rainfall intensity and either gender or age group. The female participants appeared to drive faster as compared to their male counterparts and the age group ranging from 16 to 21 years of age appeared to be the more aggressive drivers. Eighty percent $(80 \%)$ of the participants reported on the survey that they have experienced some level of hydroplaning while driving on the road. The simulator appears to provide identical results to the field data analysis, lending credence to the validity of using a driving simulator to investigate the pattern of drivers' behavior during rainfall events. The researchers recommend further validation and refinement of this study. Continuation of this project may also help Florida Department of Transportation and other agencies with future decision making, such as Variable Message Signs, determining appropriate corrective measures on existing roadway sections, and/or designing future roadway sections to reduce hydroplaning.
\end{abstract}

Keywords: Driving simulator; Light rainfall; Heavy rainfall; Highway; Hydroplaning; Speed; Suburban

\section{INTRODUCTION}

Automobile accidents are attributed to a number of causes such as driver behavior, vehicle condition, roadway condition, and environmental conditions. Some regions in the State of Florida may receive as much as 100 inches of rainfall in a calendar year. These rainfalls may occur in excess of three inches in a 24-hour period to near or greater than 10 inches. As the population in Florida increases, there is a higher demand to add additional lanes to highways to accommodate the anticipated traffic and mobility in the state. It is not uncommon to find highways with four to six lanes in each direction. As the width of the pavement increases (more lanes), more water stays on the pavement thus increasing the potential for hydroplaning. It is, therefore, of great importance to evaluate drivers' behavior during rainfall(s) in the State.

*Corresponding author's email: cvillier@fgcu.edu, Tel. +1-239-590-7479, Fax. + 1-239-590-7304 
The purpose of this study is to utilize a driving simulator to investigate the pattern of drivers' behavior during rainfall events using different geometries. Driving simulators have played an important role in traffic studies (Fitzpatrick et al., 2010; Fitzpatrick, Chrysler, Park, Iragavarapu, \& Nelson, 2012).Simulators have also been used as a tool for studies and analyses related to driving behaviors. This research utilizes participants (drivers) of varying sex and age groups, driving the simulator in a virtual world ranging from suburban to highway, with and without rainfalls and recording their driving speed. The researchers conducted a data analysis including statistical analysis to meet the objectives of this research.

\section{OBJECTIVES}

The primary objective is to evaluate drivers' behaviors, especially speed control, on conditions that simulate hydroplaning potential. The specific objectives are as follows:

- Collect and review all the pertinent literature and other information related to driving applications on roadways.

- Design and conduct a driving simulation along with an experimental design to determine drivers' responses during rainfall events.

- Conduct surveys to determine the perspective of the subjects used in this study while driving in rainfall events.

- Provide recommendations that can be used in designing roadway sections to accommodate for hydroplaning.

\section{APPROACH}

The authors conducted a literature review of previous transportation studies in driving simulators. The goal in this task was to identify the key elements required in successful simulation-based research. Field data on major highway sections throughout Florida was selected. Since rainfall data are usually available at airport locations, strategic planning ensured that the selected sections were relatively close to airport locations. The obtained data were analyzed for validity and consistency and to identify the anticipated vehicle speed that allows transportation designers to determine conditions in which potential hydroplaning may occur. The researchers simulated the parameters, such as speed and rainfall intensity, observed in the field (within the limitation of the University of Central Florida simulator). Finally, the data were analyzed in an effort to meet the objective of this study.

\section{LITERATURE REVIEW}

The cause of automobile accidents can be attributed to a number of factors such as driver behavior, vehicle condition, roadway condition, and environmental conditions. Each year, thousands of people lose their lives despite the millions of dollars spent by State and County Officials to maintain the roadway infrastructures, reduce aggressive traffic, promote driver education programs, and explore numerous other safety initiatives. In 2017, 37,133 Americans were killed in crashes involving motor vehicles. Motor vehicle crashes are a leading cause of death for Americans overall, and the number one cause of death for teenagers (Peterman, 2019).

The Federal Highway Administration gathers traffic, accident, and fatality data on all roadways throughout the nation; a total of 2,922 fatal crashes and 3,112 deaths were reported for the State of Florida in 2017 (Federal Highway Administration, 2018). Florida is the third, behind Texas and California, with the highest amount of driving-related fatalities.

In Florida, especially during the summer, rainfall between 50 to 80 inches is common. Hydroplaning is a condition where one or more tires of a vehicle completely lose contact with the pavement due to a layer of water film between the tire and the pavement surface (Al-Ahad 
Ekram \& Kane, 2018; Browne, 1975; Gunaratne et al., 2012). As a result, the car slides and skids and far too often cause injury or fatality. One important cause of hydroplaning is driving speed (Al-Ahad Ekram \& Kane, 2018; Glennon, 2006; Gunaratne et al., 2012). In 2017, speeding killed 9,717 people, accounting for more than a quarter $(26 \%)$ of all traffic fatalities that year (National Highway Traffic Safety Administration, 2019). Nearly one-half of all these fatal crashes occurred on roads with posted speed limits of $55 \mathrm{mph}$ or more (Federal Highway Administration, 2018). The chance of hydroplaning grows when the driving speed increases. In this situation, it is desirable to know how fast drivers would drive in rainfall conditions. On a dry surface, drivers may be confident in their driving and in control and likely to drive within the speed limit. However, the comfort level drops for most drivers during rainfall events. Very little information exists on how much drivers reduce their speed when it rains. It is, therefore, of great importance to determine the speed difference in rainfall conditions.

In recent years, driving simulators have played an important role in traffic studies. They have also been used as tools for studies and analyses related to driving behaviors. The use of simulators is cost-effective, safe and often the only viable method of analyzing driving behaviors, especially in situations that are difficult or impossible to reproduce in real life or on actual road conditions studies (Christoforou, Karlaftis, \& Yannis, 2012; Fox, 1998). Driving simulators offer advantages in high-security and high-repeatability. Setting road and weather conditions is easy and economically sufficient (Glennon, 2006). The use of driving simulator over time for traffic safety and operation has many advantages over similar real-world or onroad driving research, including experimental control, efficiency, expense, safety, and ease of data collection (Christoforou et al., 2012; Maeda, Kawamura, Shirakawa, Nakatsuji, \& Kumada, 2005; Morris, Craig, Achtemeier, \& Easterlund, 2019; Nilsson, 1993). In this research, a simulator called "PatrolSim", located in the RAPTER lab at the University of Central Florida was utilized. It was manufactured by L-3 Communications Inc. and is a fixedbase driving simulator.

\section{FIELD DATA ANALYSIS}

In an attempt to determine the impact of rainfall events on free-flow speed, data was obtained from Florida's Statewide 511 Website, Florida Department of Transportation (FDOT) STEWARD database, and National Oceanic and Atmospheric Administration (NOAA). The STEWARD is a database administrated by the Florida Department of Transportation. NOAA contains hourly rainfall data from multiple sites/airports in the nation including Florida. These data were analyzed to determine the impact of rainfall events on drivers' behaviors dealing with free-flow speed and traffic volume.A total of 6 sections were selected, covering a breadth of locations throughout Florida. Table 1 presents the location, mile marker, and information about the weather station used for these sites. All of the locations were within 8 miles of an airport. The posted speed limit on these sites was $65 \mathrm{mph}$ or greater. Rainfall data for the particular airport was used to complete the analysis.

Table 1 Roadway Section Used in the Study

\begin{tabular}{l|l|l|l|l|l|l}
\hline Project ID & City & District & Highway & $\begin{array}{l}\text { Mile } \\
\text { Marker }\end{array}$ & Airport & $\begin{array}{l}\text { Distance from } \\
\text { Airport }^{\mathrm{a}^{\mathrm{f}}}\end{array}$ \\
\hline 2100814 & Jacksonville & 2 & I-95 & 349.4 & Jacksonville International Airport & $8.12 \mathrm{miles}$ \\
411002 & Boca Raton & 4 & I-95 & 42.7 & Boca Raton Airport & 3.50 miles \\
420412 & Ft Lauderdale & 4 & I-595 & $\mid 10.7$ & Ft Lauderdale- Hollywood International Airport & miles \\
510611 & Orlando & 5 & I-4 & 75.8 & Orlando International Airport & 7.75 miles \\
640032 & Miami & 6 & I-195 & 1.3 & Miami International Airport & 4.50 miles \\
700321 & Tampa & 7 & I-275 & 33.8 & Tampa & 5.50 miles \\
\hline
\end{tabular}

Note:

a $1 \mathrm{mi}=1.61 \mathrm{~km}$ 


\subsection{Rainfall classification and analogy for comparison}

A significant amount of data was used for the analysis. Based on Smith, Byrne, Copperman, Hennessy, and Goodall (2004), we divided the data into light rain (intensity of 0.01 to 0.25 inches/hour) and heavy rain (intensity greater than 0.25 inches/hour). The rainfalls used for light rain in this study ranged from 0.01 to 0.24 inches/hour and 0.26 to 4.33 inches/hour for heavy rain. Traffic data was divided into peak congested weekday (daytime) conditions (7:00 am to 10:00 am and 4:00 pm to 6:00 pm); non-peak weekday (6:00 am to 9:00 pm); weekend conditions (Saturday and Sunday from 6:00 am to 9:00 pm); and night time conditions (9:00 pm to 7:00 am). We established the following analogy for comparison purposes.

- Weekday conditions

- When a rainfall event was observed on a weekday, the traffic data was compared to the same hour of the average weekday traffic of dry days (4 days) for the same week as compared to the rainfall event.

\section{- Weekend conditions}

- When a rainfall event was observed on a weekend, the traffic data was compared to the same hour of the average weekend traffic of dry days for the same day weekend of the entire month (up to 9 days) as compared to the rainfall event.

\section{- Night time conditions}

$\circ$ When a rainfall event was observed at night, the traffic data was compared to the same hour of the average night time traffic of dry days (6 days) for the same week as compared to the rainfall event.

\section{DRIVING SIMULATOR SCENARIO DEVELOPMENT}

\subsection{PatrolSim Driving Simulator}

The simulator used in this study is called PatrolSim, located in the RAPTER lab at the University of Central Florida. It was manufactured by L-3 Communications Inc. It is a fixedbase driving simulator, consisting of a realistic cockpit, a brake, a gas pedal, a transmission, and three flat-screen televisions. The simulation processes used in this study are summarized below. Steps 2 to 3 take place 60 times per second. With this rate of updating, the subject will perceive continuously updated views while driving.
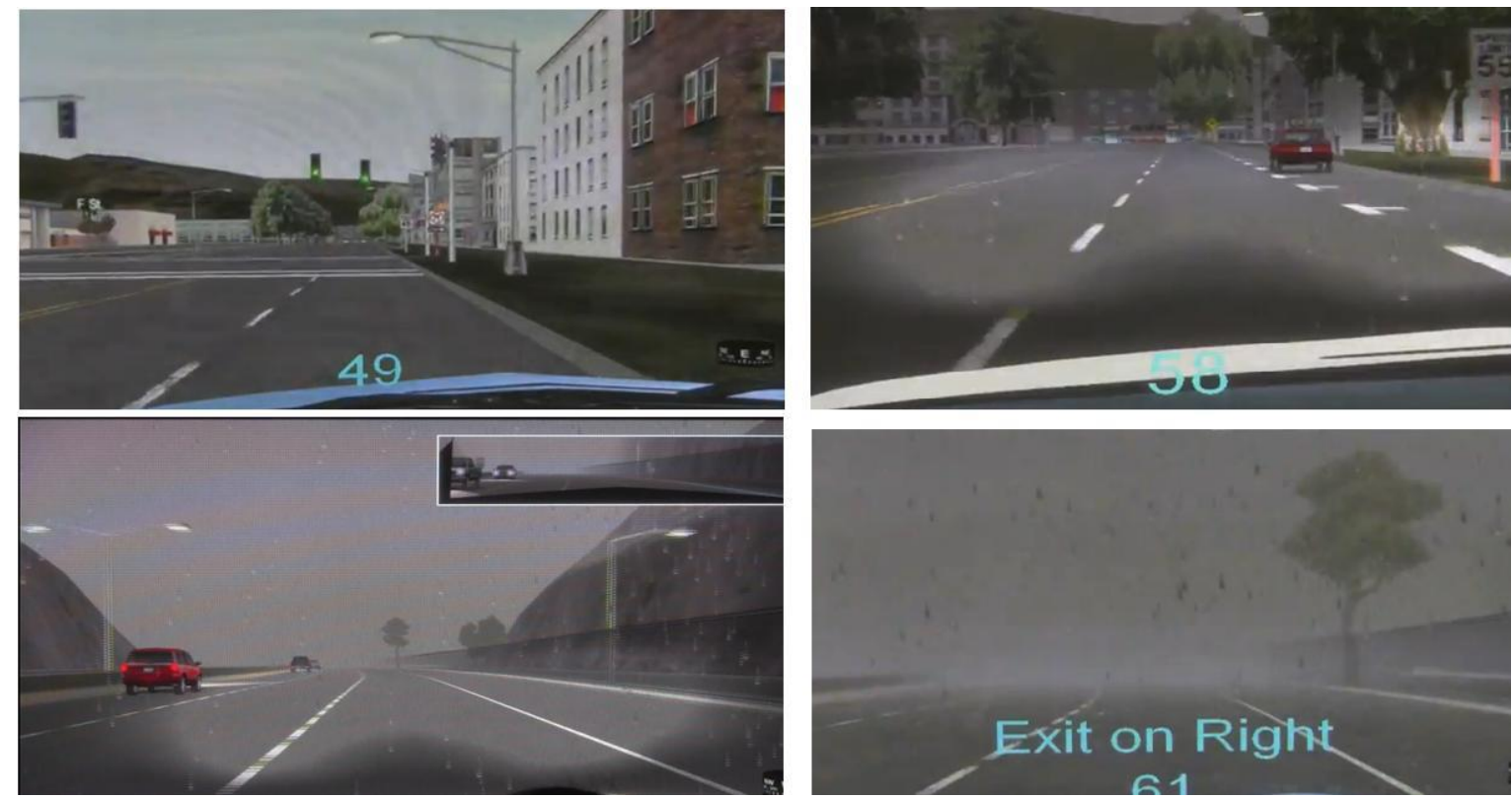

Figure 1 Screenshots of Rain Level 0 (Top Left), Level 2 (Top Right), Level 3 (Bottom Left), and Level 4 (Bottom Right) 
Figure 1 demonstrates examples of the rendered images obtained from this system.

1. The simulation software loads the scenario, created offline.

2. The simulation software finds what the driver should see on the three screens in the next cycle.

3. The simulation software renders the images on the flat-screen TVs in front of the driver.

4. The driver sees the rendered images.

5. The driver operates the gas pedal, brake and transmission on the simulator as if in a real car.

6. The simulation software collects the driver's operations in the form of numerical values. The simulation software, through a programming interface, logs user inputs and simulator's position in the virtual world to file.

\subsection{Driving Simulator Environment}

The roadway environment used in this study consists of suburban and highway with rendered images as presented in Figure 1. The speed limits used were $55 \mathrm{mph}$ and $70 \mathrm{mph}$ for suburban and highway, respectively. The researchers initially conducted a pilot study. The Lessons Learned from the pilot study were used to improve the full experiment. Minor modifications (within the capacity of the simulator) were made so that the participants could drive without disruption or significant drop in speed as much as possible. The modifications included turning off the rain trigger at locations that are difficult to maneuver, such as sharp curves, and increasing the number of scenarios to give the participants a greater familiarization with the simulator. Each participant performed the same tasks (drove both roadway sections) within their driving capability and maneuvering ability. The simulator used a passenger car and traffic simulated in the adjacent lanes and oncoming traffic.

A software component within this simulator system simulates rain effects in four rain levels ( 0 , $2-4$ ), with level 0 being the dry condition and level 4 being the heaviest rain. Level 1 simulates drizzle and may not affect driving significantly. The other three levels can cause more noticeable changes visually and were used in this experiment. The rain levels are parameterized by six coefficients as shown in Table 2. Figure 1 shows screenshots of the rain levels that are available in the simulator. In this study, level 0 (dry), level 2, level 3, and level 4 were used. To match the same rain intensity as the field data, level 2 will be referring to as "light rainfall". Since level 3 and level 4 were both used to simulate heavy rainfall in the field, they will be labeled as "heavy rainfall" throughout this document, respectively.

Table 2 Rain Levels in the UCF Driving Simulator

\begin{tabular}{|c|c|c|c|c|c|c|c|}
\hline $\begin{array}{l}\text { Rain } \\
\text { Level }\end{array}$ & $\begin{array}{l}\text { Visibility Level } \\
\text { Coef. }^{a}\end{array}$ & $\begin{array}{l}\text { Level } \\
\text { Used in } \\
\text { Study }\end{array}$ & $\begin{array}{l}\text { Thunder and } \\
\text { Lightning } \\
\text { Coef. }\end{array}$ & $\begin{array}{l}\text { Fog } \\
\text { Density } \\
\text { Coef. }\end{array}$ & $\begin{array}{l}\text { Rain } \\
\text { Audio } \\
\text { Coef. }\end{array}$ & $\begin{array}{l}\text { Friction } \\
\text { Coef. }\end{array}$ & $\begin{array}{l}\text { Visual Rain Drops } \\
\text { Coef. }\end{array}$ \\
\hline 0 & 0 (Clear) & Yes & 1 & 0 & 0 & .95 & None \\
\hline 1 & 1 (Very Light) & No & 0.5 & 0.475 & 1 & 0.91 & On \\
\hline 2 & 2 (Light) & Yes & 0.5 & 0.826 & 1 & 0.86 & Slightly heavier \\
\hline 3 & 3 (Medium & Yes & 0.5 & 0.95 & 1 & 0.81 & $\begin{array}{l}\text { Slightly heavier } \\
\text { again }\end{array}$ \\
\hline 4 & 4 (Heavy) & Yes & 0.5 & 0.99 & 1 & 0.75 & $\begin{array}{l}\text { Slightly heavier } \\
\text { again }\end{array}$ \\
\hline
\end{tabular}

Note:

${ }^{\mathrm{a}}$ Coef. $=$ Coefficient 


\subsection{Study Participants}

Twenty-nine (29) volunteers successfully completed the full experiment. Each participant was first given instructions about the simulator, signed a consent form, and also completed a questionnaire at the end of the experiment. Once the participants agreed to participate in the study and all the signed forms were in place, they were given a $\$ 10$ compensation payment. The participant sample was composed of 15 males and 14 females and ranged in age from 16 to 55 years old, and averaged 12 years of driving with a license. On average, the participants had been driving in Florida for 8 years. Except for 1 participant, the participants reported in the questionnaire that they drove slower during rainfall events as compared to dry conditions. They also reported that the amount of speed reduction while driving is a response to rainfall intensity. Eighty percent $(80 \%)$ of the participants have reported on the survey that they have experienced some level of hydroplaning while driving on the road.

\subsection{Driving Simulation Scenario and procedures}

We categorized the driving simulator scenario and procedures into six stages, each triggered to start when the drivers drove by specific locations. The participants first drove an orientation and familiarization scenario with no rainfall, to familiarize the subjects with the simulator's surrounding environment and with the route chosen for the real/actual experiment. This scenario was not used for data analysis. Then the subject drove the orientation scenario again with the simulator collecting the subject's data, such as speed, brake, etc. This data became the baseline to compare with the data collected in the rainfall conditions. In this paper, this scenario will be referred to as the baseline scenario or dry conditions. The third scenario copied everything in the baseline scenario plus rainfall conditions. In this scenario, levels 2 and 3 (See Table 2) were chosen to be the "light" and "heavy" rain respectively. In the last scenario, the subject experienced the same stages as in the previous scenario, but with heavy rain implemented by rain level 4 in the simulator.

\section{RESULT AND DISCUSSION}

\subsection{Field Data Analysis}

The data for both dry and rainy days were analyzed, dividing it into two major categories: light rain for rainfall intensity ranging from 0.01 to 0.24 inches/hour and heavy rain for rainfall intensity of greater than 0.25 inches/hour. The summary of traffic data for both light rain and heavy rain are presented in Figure 2 and Figure 3. The 95\% confidence interval error bars are also presented in the figures.

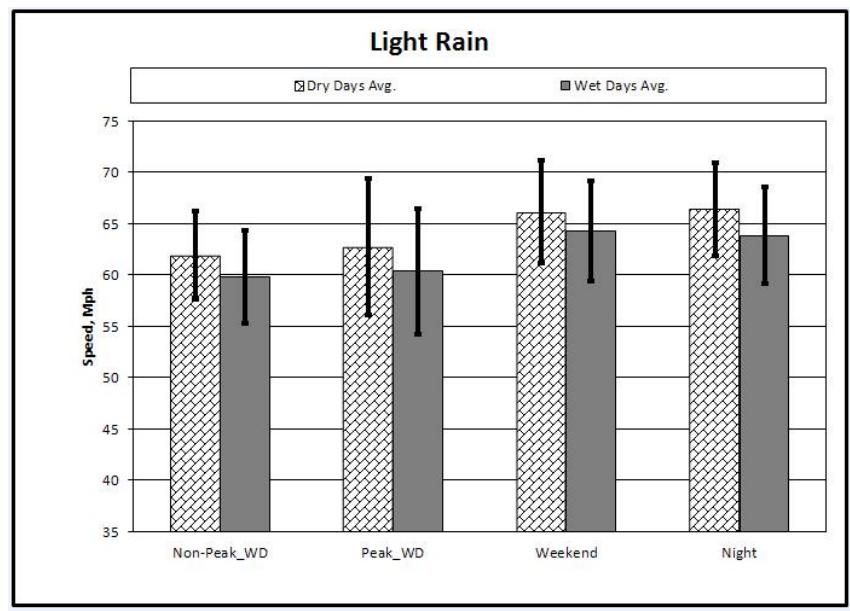

Figure 2 Average speed for statewide during light rain conditions with 95\% confidence interval error bars 


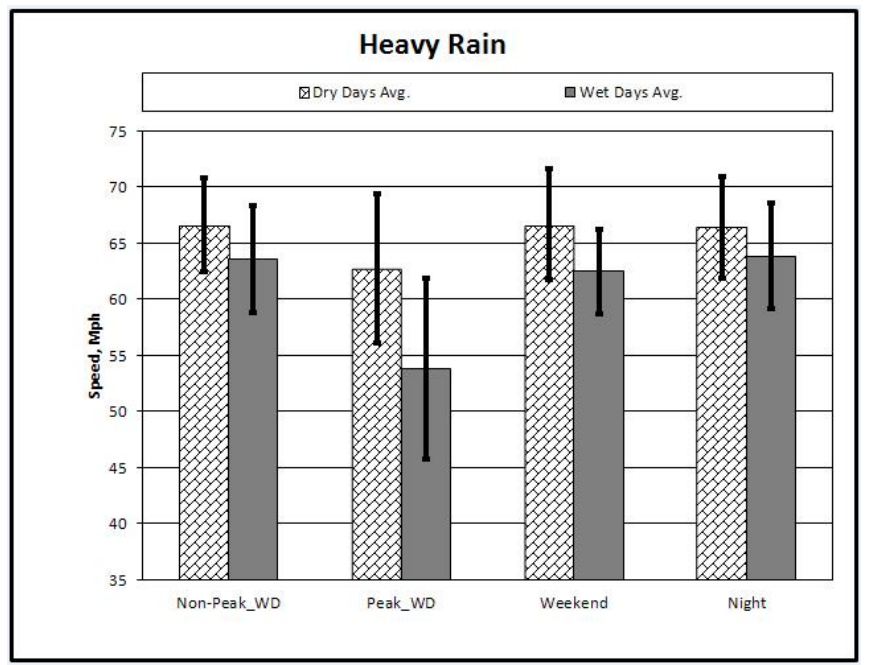

Figure 3 Average speed for statewide during heavy rain conditions with $95 \%$ confidence interval error bars

\subsection{Driving Simulator}

Once the full experiment was completed for each subject, his/her data were logged, including speed, location in the virtual world, how hard the gas and brake pedals were pressed. At this stage, the data was ready for analysis. A computer program was generated to sample the raw data at the frequency of $10 \mathrm{HZ}$. This computer program, along with engineering judgment, eliminated the simulator locations depicting sharp curves and major transitions of road geometry because these conditions resulted in sharp drops in speed that are not normal in real life. The data were analyzed for both suburban and highway roadway sections. On average, the drivers drove within the speed limit about $50 \mathrm{mph}$ and $70 \mathrm{mph}$ on both suburban and highway during dry conditions, respectively. When light rain (level 2) was simulated, it appears the divers were not affected by this rain intensity. They drove at equal speeds and many times slightly higher speeds (about $1 \mathrm{mph}$ ) as compared to dry conditions. Figure 4 and Figure 5 present the average speeds for each roadway type along with a $95 \%$ confidence interval error bars. During heavy rainfall events, the drivers slowed down $7 \mathrm{mph}$ and $9 \mathrm{mph}$ for suburban and highway sections in the simulator, respectively. Analysis of the real (field) data revealed similar behavior; on average, drivers slow down about $5 \mathrm{mph}$ during heavy rainfall events. These observations lend credence to the validity of utilizing driving simulators to investigate the pattern of drivers' behaviors during rainfall events.

On average, the participants appeared to drive within the speed limit during dry conditions. The suburban speed recorded from the participants ranged from $43 \mathrm{mph}$ to $57 \mathrm{mph}$ and from 32 to $53 \mathrm{mph}$ for light and heavy rainfall conditions, respectively. On the highway, these values ranged from $67 \mathrm{mph}$ to $78 \mathrm{mph}$ and 49 to $70 \mathrm{mph}$, respectively. The variation in speed was about 2 to $5 \mathrm{mph}$. These values were pretty reliable. The 95\% Confidence Interval Error Bars were very low. 


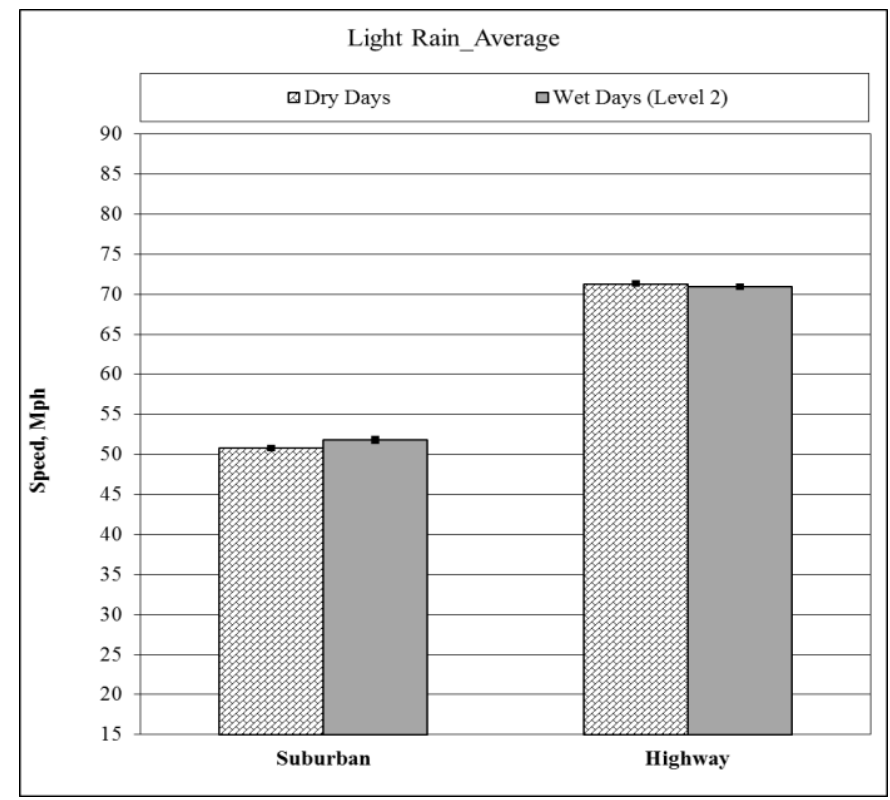

Figure 4 Average speed for all the participants during light rain conditions with $95 \%$ confidence interval error bars

\subsection{Statistical Analysis}

This section focused on determining the magnitude difference of the main effect, namely road types and rainfall conditions on speed. Another analysis determined the effect of the gender and age group of the driver along with their particular interactions with rainfall conditions on speed.

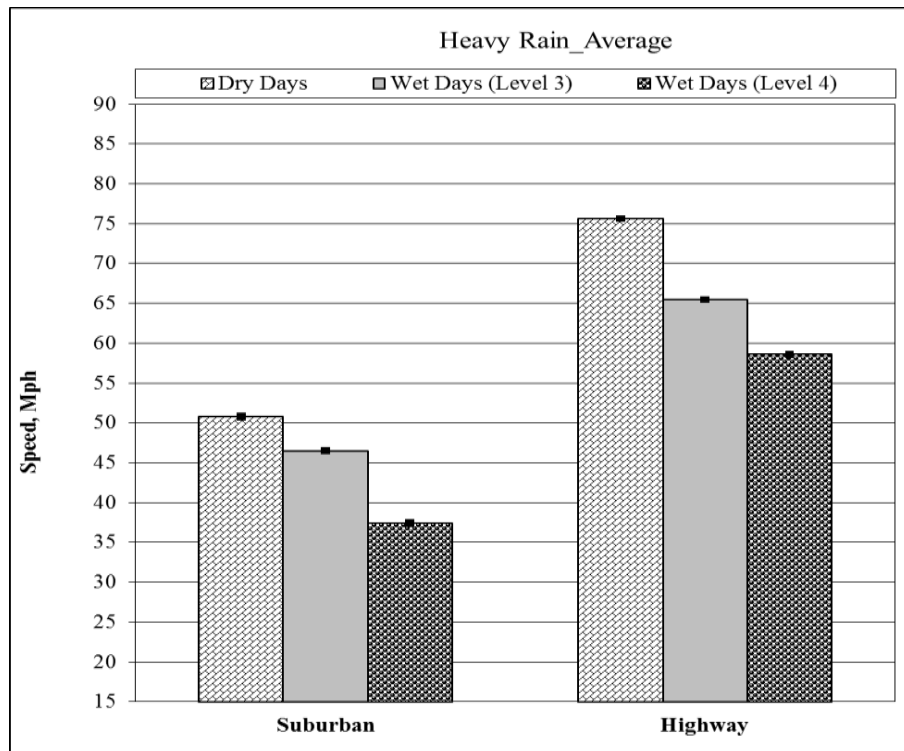

Figure 5 Average speed for all the participants during heavy rain conditions with $95 \%$ confidence interval error bars

\subsubsection{Effect of Road type and Rainfall Intensity on Drivers}

In order to compare the effect of roadway type on speed on a similar basis, the participants' actual speed was subtracted by $55 \mathrm{mph}$ and $70 \mathrm{mph}$ while driving on suburban and highway sections, respectively. A one-way analysis of variance (ANOVA) was conducted on the speed difference on suburban versus highway. In other words, the authors were interested in testing the null hypothesis that the speed difference when the subjects were driven on suburban versus highway is equal. Low P-values (less than 0.01) imply that the data do not support the null 
hypothesis. Based on the information obtained from the analysis, the main effect (roadway type) was significant on both suburban and highway, respectively. In other words, the roadway type had a significant effect on the speed difference when the participants drove the simulator. As a result, the roadway type will be treated separately throughout the rest of the analysis. The P-values were less than 0.01 .

A one-way analysis of variance also determined the effect of rainfall intensity namely dry, level 2 , level 3, and level 4 on the participants' speed on suburban and highway, respectively. The observations are illustrated by the linear statistical model as described in equation (1). Low Pvalues (less than 0.01) imply that the data do not support the null hypothesis. The results are presented in Table 3.

$$
\gamma_{i j}=\mu+\tau_{i}+\varepsilon_{i j}
$$

Where:

$\gamma_{\mathrm{ij}} \quad=$ observed response

$\mu \quad=$ overall mean effect

$\tau_{\mathrm{i}} \quad=$ effect of rainfall intensity (suburban or highway)

$\varepsilon_{\mathrm{ijk}} \quad=$ a random error component

As presented on the table, the level of rainfall intensity affects the driver's speed on both suburban and highway, respectively. The P-values were less than 0.01 . Since the results from the ANOVA support the hypothesis that the means of the rainfall intensity differ, it was of interest to determine the specific differences. In this study, Duncan's multiple range tests were used as it is quite powerful and widely used (Montgomery, 2008). A comparison between the means of rainfall intensity shows that the speed between the dry conditions and rainfall levels 3 and 4 differ significantly. Also, the speed between rainfall levels 3 and 4 differs significantly. However, the drivers were not affected by light rainfall intensity. The effect of the rainfall intensity results in a substantial drop in speed, especially for rainfall level 4 . On average, the speed dropped by $13 \mathrm{mph}$ when the drivers drove in rainfall intensity level 4 . The reduction in speed was $4 \mathrm{mph}$ for rainfall level 3 . These data match the information provided by the participants in the survey. $93 \%$ of the participants have reported that they drove slower during rainfall as compared to dry conditions. The amount of speed reduction is due to the rainfall intensity.

Table 3 Results of ANOVA for Effect of Rainfall on Speed - Suburban

\begin{tabular}{|c|c|c|c|c|c|c|}
\hline $\begin{array}{l}\text { Source of } \\
\text { Variation }\end{array}$ & $\begin{array}{l}\text { Sum of } \\
\text { Squares }^{\mathrm{a}}\end{array}$ & $\begin{array}{l}\text { Degree of } \\
\text { Freedom }\end{array}$ & $\begin{array}{l}\text { Mean } \\
\text { Square }\end{array}$ & F-Statistic & P-value & $\begin{array}{l}\text { Significant } \\
\text { at } 95 \%\end{array}$ \\
\hline Rainfall & $3843 / 3105$ & $3 / 3$ & $1281 / 1035$ & $50 / 20$ & $0.000 / 0.000$ & Yes/Yes \\
\hline Error & $2874 / 5715$ & $112 / 112$ & $25 / 51$ & & & \\
\hline Total & $6717 / 8819$ & $115 / 115$ & & & & \\
\hline
\end{tabular}

Note:

${ }^{a}$ Values for suburban / values for highway

\subsubsection{Effect of Gender on Drivers Speed}

In addition to road type and rainfall intensity, other factors may also play a rolein speed reduction. We then analysed the data utilizing a Univariate Analysis of Variance. It is a twoway ANOVA General Linear Model (GLM) with exactly two independent variables (e.g. fixed factors) (10). The objective was to differentiate the rainfall intensity and compare their means to the dry conditions. Since the participants were composed of different levels (different gender 
levels) they were also treated as factors in the ANOVA analysis. This process will determine the effects that rainfall intensity and different gender groups have on speeds while the participants were driving on suburban and highway, respectively. In other words, the authors were interested in testing the null hypothesis that the effect of rainfall intensity and different gender groups were equal and if rainfall intensity and different gender groups interacted. The observations are illustrated by the GLM as described in equation (2).

$$
\gamma_{i j}=\mu+\tau_{i}+\beta_{j}+(\tau \beta)_{i j}+\varepsilon_{i j}
$$

Where:

$$
\begin{array}{ll}
\gamma_{\mathrm{ijk}} & =\text { observed response } \\
\mu & =\text { overall mean effect } \\
\tau_{\mathrm{i}} & =\text { effect of the dry, levels } 2,3,4 \text { levels of the rainfall intensity } \\
\beta_{\mathrm{j}} & =\text { effect of male and female levels of sex group } \\
(\tau \beta)_{\mathrm{ij}} & =\text { effect of the interaction between rainfall intensity and sex group } \\
\varepsilon_{\mathrm{ijk}} & =\text { a random error component }
\end{array}
$$

The results are presented in Table 4 for suburban and highway, respectively. As presented in the previous sections, the main effect of the rainfall intensity was significant. However, based on the information presented in the table, the speed was not significantly affected by gender on either road type. The P-values were 0.02 and 0.04 for suburban and highway, respectively. Also, there is no interaction between gender type and rainfall intensity. The P-value was equal to 0.90 and 0.81 for suburban and highway, respectively. It was also found that on average, females drove about by 2 to 3 miles per hour faster as compared to the male participants.

Table 4 Results of ANOVA and Differences for Speed on Suburban

\begin{tabular}{lllllll}
\hline $\begin{array}{l}\text { Source of } \\
\text { Variation }\end{array}$ & $\begin{array}{l}\text { Type III Sum } \\
\text { of Squares }^{\mathrm{a}}\end{array}$ & $\begin{array}{l}\text { Degree of } \\
\text { Freedom }\end{array}$ & $\begin{array}{l}\text { Mean } \\
\text { Square }\end{array}$ & F-Statistic & P-value & $\begin{array}{l}\text { Significant } \\
\text { at 95\% }\end{array}$ \\
\hline Rainfall Intensity & $3823 / 3087$ & $3 / 3$ & $1274 / 1029$ & $51 / 20$ & $0.000 / 0.000$ & Yes/Yes \\
Gender Type & $142 / 214$ & $1 / 1$ & $143 / 214$ & $6 / 4$ & $0.02 / 0.04$ & No/No \\
$\begin{array}{l}\text { Rainfall * } \\
\text { Gender }\end{array}$ & $14 / 48$ & $3 / 3$ & $5 / 16$ & $0.19 / 0.32$ & $0.90 / 0.81$ & No/No \\
Error & $2716 / 5453$ & $108 / 108$ & $25 / 51$ & & & \\
Total & $259028 / 523265$ & $116 / 116$ & & & & \\
Corrected Total & $6717 / 8820$ & $115 / 115$ & & & & \\
\hline
\end{tabular}

Note:

${ }^{a}$ Values for suburban / values for highway

\subsubsection{Effect of Age Group on Drivers' speeds}

This section determined the effect of age group, along with its interaction (if existing), with rainfall intensity on drivers' speeds. Similar to the effect of gender group analysis, a Univariate Analysis of Variance along with process and model was used. Speed was used as the dependent variable and the factors were age group and rainfall variation. The results are presented in Table 5 for suburban and highway, respectively. Ithe suburban, the speed was significantly affected by age groups. The P-value was less than 0.01 . However, on the highway, the age group did not have any effect on speed. The P-value was 0.11 . No interaction between rainfall intensity and age group exited on either suburban or highway, respectively. 
Table 5 Effect of Age Group on Speed for Suburban

\begin{tabular}{|c|c|c|c|c|c|c|}
\hline $\begin{array}{l}\text { Source } \\
\text { Variation }\end{array}$ & $\begin{array}{l}\text { f Type III Sum } \\
\text { of Squares }^{\mathrm{a}}\end{array}$ & $\begin{array}{l}\text { Degree of } \\
\text { Freedom }\end{array}$ & $\begin{array}{l}\text { Mean } \\
\text { Square }\end{array}$ & F-Statistic & P-value & $\begin{array}{l}\text { Significant } \\
\text { at } 95 \%\end{array}$ \\
\hline Rainfall Intensity & $3537 / 2963$ & $3 / 3$ & $1179 / 988$ & $54 / 19$ & $0.000 / 0.000$ & Yes/Yes \\
\hline Age Group & $610 / 236$ & $2 / 2$ & $305 / 118$ & $14 / 2$ & $0.000 / 0.110$ & Yes/No \\
\hline Rainfall $*$ Age & $10 / 40$ & $6 / 6$ & $2 / 7$ & $0.08 / 0.13$ & $1.00 / 1.00$ & $\mathrm{No} / \mathrm{No}$ \\
\hline Error & $2253 / 5451$ & $104 / 104$ & $22 / 52$ & & & \\
\hline Total & $258889 / 522766$ & $116 / 116$ & & & & \\
\hline Corrected Total & $6612 / 8815$ & $115 / 115$ & & & & \\
\hline
\end{tabular}

Note:

${ }^{a}$ Values for suburban / values for highway

A comparison between the means of the age group categories has a significant effect on speed when driving on suburban. However, on the highway, no significant effect was found on the drivers' speed among the different age groups. In the suburban, the participants that were 16 to 22-year-old drove faster than any of the other participants. On average, they drove by $3 \mathrm{mph}$ and $6 \mathrm{mph}$ faster as compared to the participants that are 22 to 33-year-old and participants that are 33 or more year-old, respectively. No specific pattern on speed reduction was found between the age groups 16 to 21 and 22 to 33-year-old when driving on the highway. The 16 to 21 age group drove $3 \mathrm{mph}$ faster compared to the participants that were 33 or more. On either suburban or highway, the 22 to 33 age bracket drove $3 \mathrm{mph}$ faster than the participants that were 33-year-old or more. Subsequently, it was found that the older participants drove slower as compared to the other participants. Their speed was slower by 3 to $6 \mathrm{mph}$ than any of the other age groups on either suburban or highway, respectively.

\section{CONCLUSION AND RECOMMENDATION}

The purpose of this study was to validate the use of driving simulators to investigate the pattern of drivers' behavior during rainfall events using different geometries. A thorough literature review was conducted using published materials from transportation studies on driving simulators. An experiment was successfully designed using a driving simulator to evaluate drivers' responses, specifically speed reductions, which show similar trends in the real-world. Based on the conducted analysis, the following conclusions and recommendations were drawn:

- Drivers are not affected by light rainfall events. Heavy rainfall intensity has a significant impact on speed. On average, drivers reduced their speed 6 to $12 \mathrm{mph}$.

- There is no interaction between rainfall intensity and either gender and age group. On the simulator, the female participants appeared to drive faster as compared to their male counterparts. The age group ranging from 16 to 21-year-old was found to be the most aggressive. Eighty percent $(80 \%)$ of the participants reported on the survey that they have experienced some level of hydroplaning while driving on the road. This number is alarming. Accidents resulted from hydroplaning may be fatal.

- The simulator at UCF appears to have provided identical results when compared to the field data. These observations lend credence to the validity of utilizing a driving simulator to investigate the pattern of drivers' behaviors during rainfall events.

- The researchers recommend further validation and refinement of this approach. Since this study finds similar trends in speed reduction in the simulator as compared to real-world conditions, it supports the utilization of driving simulators to a greater extent in the research 
of hydroplaning. The PatrolSim simulator setting can be modified to effectively evaluate various human behaviors. Continuation of this project may also help Florida Department of Transportation's future decision making, such as determining appropriate corrective measures on existing roadway sections and designing future roadway sections to reduce hydroplaning. Findings from this type of research may be particularly useful at this time when many state agencies are implementing Variable Message Signs into their driver information display program.

\section{ACKNOWLEDGEMENT}

The authors would like to acknowledge the Florida Department of Transportation for their support. The authors would also like to thank FDOT research team, especially those in the Roadway Design and Hydraulics divisions for their guidance and feedback. Our appreciation goes to Ms. Lisa Hernandez and Mr. Tim Forkenbrock at UCF RAPTER Lab and the FGCU student volunteers for their participation and support on this research.

\section{REFERENCES}

Al-Ahad Ekram, P., \& Kane, S. (2018). Hydroplaning Crash Study and Mitigation Strategies Phase II. Retrieved from http://www.floridasturnpike.com/design/Documents/DocsPublications/FTE\%20Hydroplani ng\%20Study\%20Phase\%20II\%20Tech\%20Memo.pdf

Browne, A. L. (1975). Mathematical analysis for pneumatic tire hydroplaning. In Surface Texture Versus Skidding: Measurements, Frictional Aspects, and Safety Features of TirePavement Interactions: ASTM International.

Christoforou, Z., Karlaftis, M. G., \& Yannis, G. (2012). Effects of alcohol on speeding and road positioning of young drivers: Driving simulator study. Transportation research record, 2281(1), 32-42.

Federal Highway Administration. (2018). Traffic Volume Trends, January-December 2017. Retrieved from https://www.iihs.org/topics/fatality-statistics/detail/state-by-state

Fitzpatrick, K., Chrysler, S., Park, E. S., Nelson, A., Robertson, J., \& Iragavarapu, V. (2010). Driver workload at higher speeds. Retrieved from http://tti.tamu.edu/documents/0-59111.pdf

Fitzpatrick, K., Chrysler, S. T., Park, E. S., Iragavarapu, V., \& Nelson, A. A. (2012). Driver performance at high speeds using a simulator. Transportation research record, 2321(1), 88-97.

Fox, J. E. (1998). The effects of age and ATIS use on driving performance: a simulator study. Paper presented at the Proceedings of the Human Factors and Ergonomics Society Annual Meeting.

Glennon, J. (2006). Hydroplaning: The Trouble with Highway Cross Slope. Retrieved from http://www.crashforensics.com/papers.cfm?PaperID=8

Gunaratne, M., Lu, Q., Yang, J., Jayasooriya, W., Yassin, M., \& Amarasiri, S. (2012). Hydroplaning on multi lane facilities. Retrieved from

Maeda, C., Kawamura, A., Shirakawa, T., Nakatsuji, T., \& Kumada, K. (2005). Reproducibility of the vehicle vertical motion by kit driving simulator using the actual measurement data. Journal of the Eastern Asia Society for Transportation Studies, 6, 2734-2746.

Montgomery, D. C. (2008). Design and analysis of experiments, Minitab manual. In. New York: Wiley, USA.

Morris, N. L., Craig, C. M., Achtemeier, J., \& Easterlund, P. (2019). HumanFIRST Driving Simulation Educational Development. Retrieved from http://hdl.handle.net/11299/203196 
National Highway Traffic Safety Administration. (2019). Speeding. Retrieved from https://www.nhtsa.gov/risky-driving/speeding

Nilsson, L. (1993). Behavioural research in an advanced driving simulator-experiences of the VTI system. Paper presented at the Proceedings of the Human Factors and Ergonomics Society Annual Meeting.

Peterman, D. R. (2019). Federal Highway Traffic Safety Policies: Impacts and Opportunities. Retrieved from https://www.everycrsreport.com/files/20190712_R44394_4a3360b0ba85aa0a2ad7c66e668 $82 \mathrm{fb} 014 \mathrm{f} 7 \mathrm{~d} 5 \mathrm{ca} . \mathrm{pdf}$

Smith, B. L., Byrne, K. G., Copperman, R. B., Hennessy, S. M., \& Goodall, N. J. (2004). An investigation into the impact of rainfall on freeway traffic flow. Paper presented at the 83rd annual meeting of the Transportation Research Board, Washington DC. 